\title{
Limited diagnostic value of procalcitonin in early diagnosis of adult onset Still's disease
}

\author{
Ewelina Gowin ${ }^{1}$, Jacek Wysocki ${ }^{2}$ \\ ${ }^{1}$ Department of Family Medicine, Poznan University of Medical Sciences, Poznan, Poland \\ ${ }^{2}$ Department of Health Promotion, Poznan University of Medical Sciences, Poznan, Poland
}

\begin{abstract}
A 17-year-old female patient was referred to the Infectious Diseases Ward because of fever lasting for 14 days. On admission to the hospital the patient was in a generally good state, without any abnormalities on physical examination.

Laboratory investigation revealed elevated inflammatory markers. Diagnostic imaging comprising chest X-ray, abdominal ultrasonography, and echocardiography showed no abnormalities. During the hospitalization, there occurred episodes of fever with skin rash and musculoskeletal pain of the lower limbs. Procalcitonin concentrations continued to increase. C-reactive protein concentrations decreased during therapy, starting from $191 \mathrm{mg} / \mathrm{l}$. On the $23^{\text {rd }}$ day of the disease, edema of the feet, ankles, and knees appeared.

On the basis of the clinical picture and after excluding other possible causes of fever, the patient was diagnosed with adult onset Still's disease. The procalcitonin concentration was normalized after 5 days of steroid therapy. The patient was discharged under ambulatory rheumatologic supervision.
\end{abstract}

Key words: procalcitonin, fever, Still's disease.

\section{Introduction}

Fever is a common cause of medical consultations. It is especially unsettling when the fever is high and lasts longer than a couple of days. From a medical perspective, this symptom on its own is not a threatening one, since elevated temperature is a physiological response to infection. The primary goal is to establish the cause of fever and initiate the appropriate treatment. In most cases, finding the cause of fever is not difficult, based on the symptoms of infection. Other causes of prolonged fever are inflammatory diseases and neoplasms. Fever without any apparent source is a situation in which the patient experiences fever and after investigation the diagnosis remains inconclusive. This affects approximately $5-10 \%$ of children with fever, and it is usually a short-term episode [1]. An important diagnostic and therapeutic problem is fever of unknown origin (FUO). The FUO is diagnosed on the basis of the following criteria: a body temperature of $38.3^{\circ} \mathrm{C}$ or above, which lasts a minimum of three weeks (or one week during hospitalization), and no success in establishing any probable cause. In about $30 \%$ of chronic fevers, the cause is never determined [2]. In the case of fever with unknown origin, it is vital to exclude infectious causes by carrying out microbiological, serological, and molecular studies. While results are pending, infection markers such as erythrocyte sedimentation rate (ESR), C-reactive protein (CRP), and, most recently, procalcitonin (PCT) are assessed on a regular basis.

In some cases, the interpretation of these results is not obvious and requires differentiation between infectious and other reasons for these laboratory deviations.

\section{Case report}

A 17-year-old female patient was referred to the Infectious Diseases Ward from a district hospital because of prolonged fever lasting for 14 days. In the patient history, in the evening of the first day of the onset of symptoms the patient reported a temperature of $40^{\circ} \mathrm{C}$, pain

\footnotetext{
Address for correspondence:

Ewelina Gowin, Department of Family Medicine, Poznan University of Medical Sciences, Przybyszewskiego 49, 60-355 Poznan, Poland, e-mail: ewego@poczta.onet.pl
}

Submitted: 30.06.2016; Accepted: 29.08.2016 
in the lower limbs and muscular pain. The next day, the patient was without fever but developed a sore throat and had enlarged submandibular lymph nodes. The patient was consulted by her family doctor, who diagnosed a throat infection and prescribed second-generation cephalosporin (cefuroxime axetil) and ibuprofen. After a few days, the sore throat was relieved, although the fever remained. Five days later, the patient went to a gynecologist with the symptoms of intense lower abdominal pain during her menses; a gynecological examination revealed no abnormalities. On the basis of her fever for the previous 8 days and not responding to antibiotic treatment, the patient was admitted to hospital for further evaluation.

Table I. Laboratory tests results on admission

\begin{tabular}{|c|c|c|c|}
\hline Parameter & Units & Value & $\begin{array}{l}\text { Normal } \\
\text { values }\end{array}$ \\
\hline Hemoglobin & $\mathrm{g} / \mathrm{dl}$ & 14.0 & 12.10-15.10 \\
\hline Erythrocytes & $10^{6} / \mu \mathrm{l}$ & 4.92 & $4.10-5.10$ \\
\hline Platelets & $10^{3} / \mu \mathrm{l}$ & 376 & $180-430$ \\
\hline Leukocytes & $10^{3} / \mu \mathrm{l}$ & 16.54 & $3.80-10.0$ \\
\hline Neutrophils & $10^{3} / \mu 1$ & 13.2 & $2.0-7.0$ \\
\hline Neutrophils & $\%$ & 80 & $40-80$ \\
\hline Total protein & $\mathrm{g} / \mathrm{l}$ & 66 & $64-83$ \\
\hline Albumin & $\%(g / l)$ & $50.90(33)$ & $\begin{array}{c}54-65 \\
(35-52) \\
\end{array}$ \\
\hline$\alpha_{1}$-globulins & $\%(g / l)$ & $5.10(3.37)$ & $\begin{array}{c}2-3 \\
(1.10-3.7)\end{array}$ \\
\hline$\alpha_{2}$-globulins & $\%(g / l)$ & $17.0(11.22)$ & $\begin{array}{c}8-12 \\
(8.50-15)\end{array}$ \\
\hline$\beta$-globulins & $\%(g / l)$ & $11.90(7.85)$ & $\begin{array}{c}10-16 \\
(8.60-15)\end{array}$ \\
\hline$\gamma$-globulins & $\%(g / l)$ & $15.10(9.97)$ & $\begin{array}{c}10-18 \\
(9.20-18)\end{array}$ \\
\hline $\lg G$ & $g / l$ & 8.38 & 5.49-15.84 \\
\hline $\lg M$ & $g / 1$ & 1.05 & $0.23-2.59$ \\
\hline $\lg A$ & $g / l$ & 1.27 & $0.61-3.48$ \\
\hline Ferritin & $\mathrm{ng} / \mathrm{ml}$ & 173.95 & 20-150 \\
\hline Fibrinogen & 0 & 6 & $1.80-3.05$ \\
\hline $\begin{array}{c}\text { Asparagine } \\
\text { aminotransferase }\end{array}$ & $U / l$ & 14 & $0-32$ \\
\hline $\begin{array}{c}\text { Alanine } \\
\text { aminotransferase }\end{array}$ & $U / l$ & 10 & $0-33$ \\
\hline $\begin{array}{c}\text { Creatine } \\
\text { phosphokinase }\end{array}$ & $U / I$ & 40 & 29-168 \\
\hline $\begin{array}{c}\text { Lactate } \\
\text { dehydrogenase }\end{array}$ & $\mathrm{U} / \mathrm{l}$ & 178 & $125-243$ \\
\hline TSH & $\mu \mathrm{IU} / \mathrm{ml}$ & 1.26 & $0.43-4.20$ \\
\hline FT4 & $\mathrm{ng} / \mathrm{dl}$ & 1.31 & $0.79-1.34$ \\
\hline
\end{tabular}

On being admitted, the patient was in a generally good state, with good contact and orientation, no pathological changes on the skin, a body mass of $60 \mathrm{~kg}$, height of $170 \mathrm{~cm}$, body mass index (BMI) of 19.33, blood pressure of 110/70 and without any abnormalities determined during the physical examination. Past medical history of this patient was as follows: at the age of 5, she was hospitalized because of an infection of the oral cavity, urticaria and edema of the joints. At the age of 13 , the patient was admitted once again because of tonsillitis accompanied by another episode of edema of the joints. At the age of 14, the patient underwent tonsillectomy. The girl was then consulted by a rheumatologist - but the diagnosis of a connective tissue disease was not established. The consulting hematologist did not recommend bone marrow examination. The current process of diagnostic laboratory tests revealed elevated inflammatory markers: ESR, CRP, PCT. Serum ferritin concentration was slightly elevated, and serological markers indicated previous infection with Epstein-Barr virus (EBV), cytomegalovirus (CMV) and Mycoplasma pneumoniae. Immunoelectrophoresis showed increased concentrations of $\alpha$-globulins. Both antinuclear antibodies (ANA) and anti-neutrophil cytoplasmic antibodies (ANCA) were negative. On three separate occasions, blood culture did not cultivate any bacteria. Also urine culture was negative. The results are presented in Table I.

Chest X-ray, abdominal ultrasonography, and echocardiography did not reveal significant abnormalities. During hospitalization, episodes of fever with skin rash and musculoskeletal pain of the lower limbs, which responded well to $1 \mathrm{~g}$ paracetamol administered intravenously, were observed. Procalcitonin concentrations continued to increase, despite antibiotic therapy, a lack of a bacterial source of infection and the patient's generally good status between episodes of fever (Table II).

C-reactive protein concentrations decreased during therapy, starting from $191 \mathrm{mg} / \mathrm{l}$ to $18 \mathrm{mg} / \mathrm{l}$ (normal values $0-5 \mathrm{mg} / \mathrm{l}$ ) on antibiotics, and further to the normal range on steroid treatment. Procalcitonin analysis was performed by the VIDAS B.R.A.H.M.S PCT immunoassay, BioMérieux, Paris, France). On the $15^{\text {th }}$ day of illness, the patient complained of vision loss. However, subsequent ophthalmologist examination and computed tomography of the head did not reveal any pathologies. On the $10^{\text {th }}$ day of hospitalization ( $23^{\text {rd }}$ day of the disease), edema of the feet, ankles, and knees appeared, with edema of the feet persisting for the next few days. On the basis of the clinical picture and after excluding any other possible causes of fever, especially infections, the patient was diagnosed with adult onset Still's disease (AOSD); steroid therapy was initiated, and antibiotics 
Table II. Inflammatory markers results

\begin{tabular}{|cccccccc|}
\hline & \multicolumn{4}{c}{ Antibiotic treatment } & \multicolumn{3}{c|}{ Steroid treatment } \\
\hline Treatment & Day 1 & Day 5 & Day 8 & Day 10 & Day 12 & Day 2 & Day 5 \\
\hline Hospitalization days & 1 & 5 & 8 & 10 & 12 & 14 & 17 \\
\hline Procalcitonin $(\mathrm{ng} / \mathrm{ml})$ & 3.0 & 2.19 & 27.01 & 38.11 & 13.85 & 2.87 & 0.15 \\
\hline CRP $(\mathrm{mg} / \mathrm{l})$ & 191.0 & 89.63 & 91.12 & 68.21 & 18.02 & 10.0 & 4.24 \\
\hline ESR $(\mathrm{mm} / \mathrm{h})$ & 21 & 41 & & & & & 41 \\
\hline Leukocytes $\left(10^{3} / \mu \mathrm{l}\right)$ & 16.54 & 9.62 & 12.39 & & 8.70 & & 16.54 \\
\hline Neutrophils $10^{3} / \mu \mathrm{l}(\%)$ & 13.23 & 7.02 & 10.52 & & 5.86 & 11.49 \\
& $(80)$ & $(73)$ & $(85)$ & & $(67.4)$ & & $(69.5)$ \\
\hline
\end{tabular}

were discontinued. The procalcitonin concentration of $13 \mathrm{ng} / \mathrm{ml}$ (normal values < $0.5 \mathrm{ng} / \mathrm{ml}$ ) was normalized after 5 days of steroid therapy. The patient was discharged under ambulatory rheumatologic supervision.

\section{Discussion}

This case illustrates the difficulties of diagnosing AOSD, mainly because of the lack of specific and sensitive diagnostic markers. Furthermore, symptoms appear progressively over time, along with episodes of fever. Diagnosis is based on the presentation of typical symptoms (fever, generalized rash, joint pain) and after excluding other causes such as infections, malignancies or rheumatic diseases. Thus the diagnosis of Still's disease is delayed, on average 6 months from the presentation of the first symptoms $[3,4]$. Currently, there are several scales used for diagnosing Still's disease. The most sensitive is the Yamaguchi scale, which describes what first needs to be excluded to be able to diagnose Still's disease [5]. Another more specific scale, which was developed by Fautrel [6], requires measurement of glycosylated ferritin. The third scale, created by Cush et al. [7], takes into consideration the timeline in which symptoms appear at a minimum of 12 weeks, but for certainty in the diagnosis, 6 months are required. On the Yamaguchi scale, which requires 5 criteria, this patient fulfilled 7 (4 major: fever, arthralgia, typical rash, leukocytosis; and 3 minor: sore throat, lymphadenopathy, negative ANA) [5]. On the Fautrel scale she met 5 criteria (4 major: fever, arthralgia, transient erythema, pharyngitis; and 1 minor: leukocytosis), where 4 major or 3 major and 2 minor criteria are required for diagnosis. On the Cush scale, the patient scored 11 points, where 10 are required. Laboratory results showed high concentrations of ferritin. A threshold of 5 times the normal value is suggestive of AOSD, but increased concentrations of ferritin can be detected in other conditions such as macrophage activation syndrome, severe antiphospholipid syndrome and septic shock. Fautrel et al. [6] confirmed the usefulness of measuring glycosylation of ferritin for diagnosing AOSD. The sensitivity of a glycosylated ferritin concentration below $20 \%$ is $43 \%$ and specificity is $93 \%$. Moreover, ferritin is not only a biomarker of inflammation but may also play a role in regulating the immune response. Reduced suppressive function of ferritin enriched in $\mathrm{H}$ subunits may predispose to inflammatory processes. An imbalance between the concentrations of ferritin enriched in $\mathrm{H}$ subunits and ferritin enriched in $L$ subunits in bone marrow and liver biopsies correlates with the severity of disease [8]. The elevated concentrations of alpha-globulin observed in our patient were caused by increased concentrations of acute phase reactants, and are commonly seen in inflammatory conditions [3]. The patient's and family's medical histories were both negative for suspected rheumatic diseases. However, once the parents were informed that Still's disease was being considered as a diagnosis, they remembered that a few years earlier, the patient had been consulted by a rheumatologist for joint pain in her lower limbs. Despite this, at that time rheumatic causes were excluded.

The etiology and triggering factors for AOSD have not been established, although many infectious agents are detected in patients with AOSD [3]. Our patient had serology markers indicating past infection with EBV and Mycoplasma, both of which can trigger an autoimmune response.

Fever of unknown origin is usually the commonest reason for patients with Still's disease to seek medical help. High fever is observed in over $95 \%$ of patients [4]. A typical patient has one or two episodes of fever per day, with a temperature exceeding $39^{\circ} \mathrm{C}$. Our patient experienced fever every two days, although between episodes she was in good health, and made no complaints. Rash and arthralgia were short-term and responded well to paracetamol.

Careful observation of fever episodes is crucial for AOSD diagnosis. In the case described, increasing con- 
centrations of procalcitonin suggested a bacterial infection, which led to the decision to continue antibiotic therapy despite negative cultures. Procalcitonin is synthesized as a precursor for calcitonin mainly by the thyroid cells, and it also serves as a mediator to cytokines. In 1990, it was observed that procalcitonin increases when there is a bacterial infection. This increase is not stopped by glucocorticosteroids [9]. Interleukin 1 (IL-1) provides a strong stimulus of PCT, whereas tumor necrosis factor (TNF) and interferon $\gamma$ (IFN- $\gamma$ ) reduce the production of PCT. Procalcitonin is used to differentiate between bacterial and viral infections as in bacterial sepsis, procalcitonin is synthesized by the spleen, leukocytes, lungs, liver, and kidneys. An increase in calcitonin or calcium is not observed as a reaction to increased procalcitonin concentrations. Within about 6-12 hours of contact with bacterial factors, the concentration of procalcitonin increases, peaking at 24 hours. Procalcitonin half-life is 24 hours, and therefore concentrations should be checked every two days after the initiation of antibiotics to monitor the progression of the illness.

Many studies have confirmed the usefulness of procalcitonin as a marker of sepsis [9-12]. It is a useful indicator for early diagnosis of septic patients. In fact, a meta-analysis showed the superiority of procalcitonin over CRP in the rapid detection of sepsis [9]. The specificity and sensitivity of procalcitonin in patients with systemic inflammatory response syndrome (SIRS) of bacterial etiology are $78 \%$ and $97 \%$, respectively [10]. Procalcitonin has proven its effectiveness in distinguishing bacterial from viral etiology of respiratory infections. Patients with symptoms of bronchitis or pneumonia and with low procalcitonin levels do not show any additional benefit from antibiotic treatment. In the diagnosis of pneumonia, a procalcitonin cut-off value of $0.25 \mu \mathrm{g} /$ / shows $96 \%$ specificity and $40 \%$ sensitivity [13]. The advantage of procalcitonin is that it reduces the use of antibiotics. Its usefulness has also been demonstrated for monitoring patients in intensive care units and in making decisions regarding whether to continue antibiotic therapy in patients with severe pneumonia. Scire et al. [4] carried out a study of 44 patients with systemic diseases. Their findings showed that procalcitonin has good sensitivity (74\%) and specificity (89\%) in terms of identifying the bacterial etiology of fever. Specificity was much higher compared to CRP (10\%) or ESR (5\%) [10]. Other authors observed high concentrations of procalcitonin in patients who were under severe stress, following trauma or surgery [14]. Deceptively low concentrations of procalcitonin are observed in patients in the initial stages of bacterial infections, or in the case of a localized process (i.e. abscess). Procalcitonin measurements allow the possibility of a bacterial infection and its severity to be determined. In many patients with serious conditions, procalcitonin does not provide additional diagnostic data, and thus does not affect therapeutic decision making.

In the patient described, procalcitonin concentrations remained high despite the good general condition, a normal body temperature, and the absence of musculoskeletal symptoms. The presentation of joint inflammation in the foot was the most important factor that led to the initiation of steroid therapy. An excess of laboratory results prolonged the diagnostic process and led to prolonged antibiotic treatment. Withholding antibiotics and introducing steroids resulted in a decrease in the procalcitonin concentration.

Our case shows the limitations in the use of procalcitonin for the diagnosis of prolonged fever. In patients with systemic diseases, elevated concentrations of procalcitonin cannot serve as a marker of bacterial infection [12]. In fever of unknown origin, procalcitonin does not allow a clear differentiation between bacteria and noninfectious etiology.

The clinical significance of increased concentrations of procalcitonin in a patient with Still's disease is not established, and there are few reports on the use of procalcitonin in the diagnosis of systemic diseases [12, 13]. Among patients previously diagnosed with AOSD, high concentrations of PCT can be observed without apparent bacterial infection [4, 15]. Okada et al. [16] obtained similar results for patients with Kawasaki disease. An increase in PCT concentrations in patients with AOSD can be interpreted as a response to a stimulus other than infection [14]. It is suggested that cytokines play an important role in procalcitonin release, and also proinflammatory cytokines - interleukin $1 \beta$, interleukin 6 , interleukin 18, TNF and IFN- $\gamma$ - are increased in Still's disease. In the described patient we were not able to check the concentration of interleukin 6, interleukin 18, TNF or IFN- $\gamma$, although it would have been very useful. However, these parameters are not measured as a routine diagnostic procedure. Procalcitonin is released in response to most of them, while IFN- $\gamma$ attenuates its production. Therefore, the concentration of procalcitonin in Still's disease depends on the balance between IL-1 $\beta$, IL-6, TNF and IFN- $\gamma$. Over-production of interleukin 18 is related to high ferritin concentrations [3].

\section{Summary}

This case illustrates the possibility of increasing concentrations of procalcitonin in acute systemic disease in the absence of infection. Thus the diagnosis of fever in patients with known or suspected systemic disease still remains a difficult task. The concentration of procalcitonin, although it is recognized as a marker of severe sep- 
sis and septic shock, and a useful parameter to monitor the effectiveness of antibiotic treatment, may also be increased in autoimmune diseases such as AOSD without confirmed infection. Interpretation of PCT requires a full evaluation of clinical symptoms, monitoring the dynamics of changes in concentration, and interpretation in relation to other results of inflammatory markers.

There are insufficient data assessing the usefulness of PCT in patients with fever of unknown origin. However, low concentrations of procalcitonin are used to exclude systemic severe bacterial infection. In conclusion, procalcitonin is not an ideal marker of bacterial infection.

The authors declare no conflict of interest.

\section{References}

1. Gaeta GB, Fusco FM, Nardiello S. Fever of unknown origin: A systematic review of the literature for 1995-2004. Nucl Med Commun 2006; 27: 205-211.

2. Tolan RW Jr. Fever of unknown origin: a diagnostic approach to this vexing problem. Clin Pediatr 2010; 49: 207-213.

3. Gerfaud-Valentin M, Jarmilloux Y, Seve P. Adult-onset Still's disese. Autoimmun Rev 2014; 13: 708-722.

4. Scire CA, Cavagna L, Perotti C, et al. Diagnostic value of procalcitonin measurement in febrile patients with systemic autoimmune diseases. Clin Exp Rheumatol 2006; 24: 123-128.

5. Yamaguchi M, Ohta A, Tsunematsu T, et al. Preliminary criteria for classification of adult Still's disease. J Rheum 1992; 19: 424-430.

6. Fautrel B, Zing E, Golmard JL, et al. Proposal for a new set of classification criteria for adult-onset still disease. Medicine 2002; 81: 194-200.

7. Cush JJ, Medsger TA Jr, Christy WC, et al. Adult-onset Still's disease. Clinical course and outcome. Arthritis Rheum 1987; 30: 186-194.

8. Ruscitti P, Ciapriani P, Di Benedetto P, et al. Increases level of $\mathrm{H}$-ferritin and its imbalance with L-ferritin in bone marrow and liver of patients with adult onset Still's disease, developing macrophage activation syndrome, correlate with the severity of the disease. Autoimmun Rev 2015; 14: 429-437.

9. Müller B, Harbarth S, Stolz D, et al. Diagnostic and prognostic accuracy of clinical and laboratory parameters in community-acquired pneumonia. BMC Infect Dis 2007; 7: 10.

10. Wacker C, Prkno A, Brunkhorst FM, et al. Procalcitonin as a diagnostic marker for sepsis: a systemic review and meta-analysis. Lancet Infect Dis 2013; 13: 426-435.

11. Schuetz P, Albrich W, Mueller B. Procalcitonin for diagnosis of infection and guide to antibiotic decisions: past, present and future. BMC Med 2011; 9: 107.

12. Gendrel D, Raymond J, Assicot M, et al. Measurement of procalcitonin levels in children with bacterial or viral meningitis. Clin Infect Dis 1997; 24: 1240-1242.

13. Woodhead M, Blasi F, Ewig S, et al. Guidelines for the management of adult lower respiratory tract infections. Eur Respir J 2005; 26: 1138-1180.
14. Mahroum N, Mahagna H, Amital H. Diagnosis and classification of adult Still's disease. J Autoimmun 2014; 48: 34-37.

15. Shin KC, Lee YJ, Kang SW, et al. Serum procalcitonin measurement for detection of intercurrent infection in febrile patients with SLE. Ann Rheum Dis 2001; 60: 988-989.

16. Okada Y, Minakami H, Tomomasa T, et al. Serum procalcitonin concentration in patients with Kawasaki disease. J Infect 2004; 48: 199-205. 